\title{
Lesões macroscópicas e causas de condenação de carcaças e vísceras de bovinos abatidos na microrregião de Garanhuns, Pernambuco, Brasil
}

\author{
[Macroscopic lesions and causes for condemnation of cattle carcasses and viscera in the \\ microregion of Garanhuns, Pernambuco, Brazil]
}

\section{"Artigo Científico/Scientific Article"}

\author{
Tássio José de Oliveira Almeida, Stephanie Caroline Gueiros Silva, \\ Márcia Bersane Araújo de Medeiros Torres, Marcos Pinheiro Franque*
}

Unidade Acadêmica de Garanhuns, Universidade Federal Rural de Pernambuco, Recife-PE, Brasil.

*Autor para correspondência/Corresponding author: E-mail: marcosfranque@yahoo.com.br

\begin{abstract}
Resumo
A realização do estudo teve como objetivo identificar e quantificar as lesões macroscópicas e causas de condenação de carcaças e vísceras durante o abate de bovinos em abatedouro público da microrregião de Garanhuns, no ano de 2014. Durante as visitas foram registradas alterações anatomopatológicas verificadas na avaliação macroscópica de carcaças e vísceras condenadas. Nesse período, foi acompanhada a inspeção do abate de 833 bovinos, dos quais, em $24,85 \%$ (207/833) foi identificado ao menos um tipo de alteração determinante de condenação parcial ou total. Foram registradas 247 condenações: 98,38\% (243/247) de vísceras, das quais 72,06\% par de pulmões, 20,65\% fígado, 4,05\% coração e 1,62\% par de rins, e 1,62\% (4/247) de carcaças, das quais 0,81\% (2/247) condenação parcial (pernil) e $0,81 \%$ (2/247) condenação total. Nestas condenações, foram identificadas 336 lesões e/ou causas de condenação, visto que em algumas peças condenadas foi identificado mais de um tipo de lesão determinante de condenação. Na avaliação macroscópica, foi identificado nos pulmões o maior número de lesões macroscópicas e/ou causas de condenação, 72,35\% (246/336) do total. As principais lesões e/ou causas de condenações em carcaças ou vísceras, identificadas no presente estudo, foram: enfisema pulmonar (14,28\%), aspiração de sangue $(5,28 \%)$, abscessos hepáticos $(3,72 \%)$ e hemorragia petequial pulmonar (3,24\%). Muitas das lesões observadas ocorrem devido a falhas no processo de abate, o que faz necessário maiores cuidados no manejo pré-abate e no emprego das técnicas de abate. Ainda, este estudo reforça a importância do registro adequado das causas de condenação, para que se possa monitorar as características sanitárias do rebanho bovino da região, bem como o emprego das técnicas de abate.
\end{abstract}

Palavras-Chave: inspeção de carnes; lesões anatomopatológicas; abatedouro.

\begin{abstract}
The objective of this study was to identify and quantify macroscopic lesions and causes for condemnation of carcasses and viscera during cattle slaughter in the public slaughterhouse of the microregion of Garanhuns, in the year 2014. During the visits, anatomopathological alterations were quantified via macroscopic evaluation of condemned carcasses and viscera. During this period, 833 cattle carcasses were inspected at slaughter, of which $24.85 \%$ (207/833) presented at least one type of a determinant alteration for partial or total condemnation. From the total of 247 condemnations, $98.38 \%$ (243/247) were viscera, of which $72.06 \%$ lungs, $20.65 \%$ liver, $4.05 \%$ heart and $1.62 \%$ kidneys, and $1.62 \%$ (4/247) carcasses, of which $0.81 \%(2 / 247)$ partial condemnation (gammon) and $0.81 \%$ (2/247) total condemnation. In these observations, some condemned pieces had more than one type of lesion, resulting in 336 identified lesions and/or causes of condemnation. On macroscopic evaluation, the largest number of macroscopic lesions and/or causes of condemnation were identified in lungs, 72.35\% (246/336) of the total. Pulmonary emphysema (14.28\%), aspiration of blood (5.28\%), liver abscesses $(3.72 \%)$ and pulmonary petechial hemorrhage $(3.24 \%)$ were the main lesions and/or causes for condemnation of carcasses and viscera, identified in the present study. Many of the injuries observed occur due to failures in the slaughter process, which requires improvement in pre-slaughter management and in the use of slaughter techniques. Furthermore, this study reinforces the importance of adequate registration of condemnation causes in order to monitor the health status of cattle herds in the region, as well as the use of slaughter techniques.
\end{abstract}

Keywords: meat inspection; anatomopathological lesions; slaughterhouse. 


\section{Introdução}

Os problemas sanitários existentes na produção de bovinos podem comprometer a qualidade dos produtos cárneos e gerar sérios danos à saúde do consumidor, tornando-se um problema de saúde pública. Para que os consumidores não tenham acesso a produtos que possam representar riscos à sua saúde, é imprescindível a oportuna e adequada inspeção sanitária realizada pelo médico veterinário nos estabelecimentos de abate, para impedir que produtos inadequados sejam comercializados (Santos et al., 2001). Por outro lado, essas condenações geram prejuízos econômicos diretos para a indústria frigorífica (Fruet et al., 2013) e demais setores da cadeia produtiva da carne.

As lesões determinantes de condenação, avaliadas no processo de inspeção, podem ocorrer por questões sanitárias, falhas de manejo na propriedade de origem, no transporte ou no processo de abate. As falhas tecnológicas que ocorrem no processo de abate podem ser chamadas de "tecnopatias" (Sodré et al., 2011). Em um matadouro de bovinos do Acre, foi relatado um percentual de condenação de $71,05 \%$ dos pulmões, $4,45 \%$ dos rins e $29,97 \%$ em decorrência de tecnopatias (Israel et al., 2014). Assim, o correto e adequado registro dessas lesões auxilia na identificação de falhas no emprego de técnicas de manejo ou abate e pode indicar a necessidade de regulagem de equipamentos e capacitação dos funcionários envolvidos nas operações de abate, de forma que essas falhas sejam minimizadas. A identificação das causas de condenação também é uma forma de avaliar a condição sanitária do rebanho, o que possibilita a adoção de medidas preventivas nas propriedades e adequação do manejo de criação, reduzindo então, as perdas econômicas decorrentes de condenações (Lima et al., 2007). Desta forma, o registro das condenações torna-se importante fonte de informação nosológicas, o que tem sido cada vez mais indicado no modelo de gestão de qualidade mundialmente recomendado para a cadeia produtiva da carne (Pinto, 2008).

Apesar dos cortes cárneos serem as frações mais valorizadas, aceitas e consumidas pela população, vísceras (miúdos) também são destinadas ao consumo humano, sendo fontes proteicas alternativas para a população mundial em expansão. Outro benefício é que, de forma geral, seu valor de comercialização é inferior aos cortes cárneos, possibilitando o maior acesso pela população de menor poder aquisitivo. Além disso, esses subprodutos também podem ser utilizados para fabricação de alimentos processados (Fruet et al., 2013).

De acordo com a literatura, o maior número de condenações está relacionado ao fígado, pulmão (Fruet et al., 2013) e rim (Silva et al., 2013). Porém, as principais perdas econômicas decorreram das condenações de fígado (Fekadu et al., 2012; Fruet et al., 2013; Edo et al., 2014; Efrem et al., 2015) e carcaça (Fruet et al., 2013; Efrem et al., 2015). Além disso, trabalhos realizados em abatedouros de diferentes regiões do Brasil (Castro e Moreira, 2010; Vieira et al., 2011; Fruet et al., 2013; Israel et al., 2014) e em outras partes do mundo (Fekadu et al., 2012; Edo et al., 2014; Moje et al., 2014; Efrem et al., 2015; Tembo e Nonga, 2015) relataram diversas causas e frequências de condenação, devido as diferenças entre as regiões e o período de estudo. Portanto, além das condenações de carcaças, os descartes de vísceras geram importante impacto econômico, com perdas substanciais ao setor da carne bovina.

O estado de Pernambuco tem importante destaque na bovinocultura nacional, com o quarto maior efetivo de bovinos do Nordeste, estimado em mais de 1,9 milhões de animais em 2014 (IBGE, 2016). No entanto, há uma escassez de estudos que abordem as causas de condenação no estado, especialmente na microrregião de Garanhuns. Devido às características do rebanho e da importância do abatedouro de bovinos para microrregião de Garanhuns, a realização do presente estudo teve como objetivo identificar e quantificar as lesões macroscópicas nos órgãos e carcaças condenadas durante a inspeção do abate de bovinos, em abatedouro público da microrregião de Garanhuns, Pernambuco, no ano de 2014.

\section{Material e Métodos}

O presente estudo foi conduzido no período de junho a dezembro de 2014, com a realização de duas visitas semanais (quartas e sextas-feiras) ao abatedouro da cidade de Garanhuns - PE, para o acompanhamento do abate dos bovinos. O estabelecimento realizou o abate de bovinos dos municípios de Garanhuns, Lagoa do Ouro, Correntes e Lajedo, localizados na microrregião de Garanhuns. Ao todo, foram realizadas 29 visitas e o acompanhamento dos procedimentos oficiais de 
inspeção higiênica, sanitária e tecnológica de 833 bovinos.

Durante o abate, foi realizada a avaliação macroscópica dos órgãos e carcaças, com base na visualização da peça, apreciação do volume, consistência, aspecto, coloração, palpação e incisão do parênquima dos órgãos e cortes longitudinais das lesões, quando necessário, segundo as especificações do Regulamento da Inspeção Industrial e Sanitária de Produtos de Origem Animal - RIISPOA (BRASIL, 2017).

Todas as lesões e/ou causas de condenação verificadas nas vísceras ou carcaças condenadas foram registradas individualmente, sendo, por vezes, identificadas mais de uma lesão na mesma víscera ou carcaça. Outra situação registrada foi o fato da víscera não ter lesão, porém intimamente relacionada com lesões de vísceras adjacentes ou carcaça, o que também ocasionou sua condenação. Os dados obtidos foram devidamente tabulados e analisados por meio de estatística descritiva, quanto à média, frequência absoluta e relativa (Sampaio, 2002).

\section{Resultados e Discussão}

Durante o período de estudo, foi acompanhada a inspeção do abate de 833 bovinos, o que representou uma média de 28,7 animais por visita, dos quais $207(24,85 \%)$ apresentaram algum tipo de lesão determinante de condenação. Como disposto na Tabela 1, foram registradas 247 condenações, das quais $243(98,38 \%)$ relativas a vísceras $(72,06 \%$ par de pulmões, $20,65 \%$ fígados, $4,05 \%$ corações e $1,62 \%$ par de rins), duas $(0,8 \%)$ condenações totais de carcaça e duas $(0,8 \%)$ condenações parciais de carcaça (pernil). Por outro lado, foi observado um total de 336 lesões e/ou causas de condenação. $\mathrm{O}$ maior número de lesões/causas em relação ao de condenações se deve ao fato de uma mesma víscera, na maioria das vezes, ter apresentado mais de uma lesão.

Tabela 1. Condenações de carcaças e vísceras durante o abate de bovinos em abatedouro municipal de Garanhuns - PE, no ano de 2014.

\begin{tabular}{|c|c|c|c|c|}
\hline Parte condenada & $\mathbf{N}$ & $\%$ & FCTA* & NLCC*** \\
\hline Pulmões (par) & 178 & 72,06 & 21,37 & 246 \\
\hline Fígado & 51 & 20,65 & 6,12 & 70 \\
\hline Coração & 10 & 4,05 & 1,20 & 12 \\
\hline Rins (par) & 04 & 1,62 & 0,48 & 4 \\
\hline Rejeição total de carcaça & 02 & 0,81 & 0,24 & 2 \\
\hline Rejeição parcial de carcaça (pernil) & 02 & 0,81 & 0,24 & 2 \\
\hline Total & 247 & 100 & - & 336 \\
\hline
\end{tabular}

*FCTA=Frequência de Condenação no Total de Abates; **Número de Lesões e/ou Causas de Condenação.

O par de pulmões foi condenado em $21,37 \%$ $(178 / 833)$ dos bovinos abatidos. Tais descartes representaram $72,06 \%$ do total de condenações (Tabela 1). Resultado semelhante, de $24,9 \%$ foi relatado em Santa Maria, RS (Fruet et al., 2013), 24,8\% em Adama, Etiópia (Edo et al., 2014) e 17,7\% em Uberlândia, MG (Silva et al., 2013), porém, o resultado foi superior aos $10,5 \% \mathrm{em}$ Dodoma, Tanzânia (Tembo e Nonga, 2015). O par de pulmões, além da maior frequência de condenação, apresentou a maior diversidade de lesões/causas de condenação, com um total de 14 tipos (Tabela 2). Nos pulmões condenados, foram observados um $(57,86 \%)$, dois $(37,07 \%)$, três $(4,5 \%)$ ou até quatro $(0,56 \%)$ tipos de alterações/situações passíveis de condenação numa mesma peça, o que totalizou 246 e representou $73,2 \%$, em vísceras e carcaças.
Os pulmões devem ser condenados caso apresentem lesões patológicas de origem inflamatória, infecciosa, parasitária, traumática ou pré-agônica (BRASIL, 2017). Este último caso foi o mais importante na condenação de pulmão, uma vez que a principal lesão foi o enfisema pulmonar, responsável por $48,37 \%$ do total de lesões identificadas nas condenações da víscera (Tabela 2). Esse resultado corroborou com outros estudos, que identificaram o enfisema como a principal lesão pulmonar em matadouro de bovinos (Fruet et al., 2013; Tembo e Nonga, 2015). Esta lesão é caracterizada pelo excesso de ar nos pulmões, o que resulta em uma distensão anormal dos alvéolos e consequente destruição da parede alveolar (Santos e Guedes, 2010). Outras vezes, pela falta de ventilação colateral na espécie bovina, o ar em excesso é forçado a entrar no tecido conjuntivo 
interlobular, o que provoca a distensão dos septos. Um importante fator que predispõe ao enfisema é o movimento respiratório forçado, em que o ar sob alta pressão invade o tecido conjuntivo frouxo dos septos interlobulares (López, 2009), como ocorre na fase pré-agônica, no momento do abate. Dos pulmões com tal alteração, 46,21\% (64/119) apresentaram-na em associação com uma ou mais lesões. As principais associações observadas foram: 40,62\% (26/64) enfisema e aspiração de sangue; $37,5 \%$ (24/64) enfisema e hemorragia petequial; e 6,25\% (4/64) enfisema, aspiração de sangue e hemorragia petequial.

Tabela 2. Lesões macroscópicas e/ou causas de condenação em pulmões de bovinos abatidos no abatedouro público de Garanhuns - PE, no ano de 2014.

\begin{tabular}{clccc}
\hline Parte condenada & \multicolumn{1}{c}{ Causa e/ou lesão } & N & \% & FCTA* \\
\hline Pulmões (par) & Enfisema pulmonar & 119 & 48,37 & 14,28 \\
& Aspiração de sangue & 44 & 17,88 & 5,28 \\
& Hemorragia petequial & 27 & 10,97 & 3,24 \\
& Abscessos pulmonares & 10 & 4,06 & 1,20 \\
& Lesões sugestivas de tuberculose & 9 & 3,65 & 1,08 \\
& Congestão pulmonar & 6 & 2,43 & 0,72 \\
& Pneumonia & 6 & 2,43 & 0,72 \\
& Atelectasia & 6 & 2,43 & 0,72 \\
& Edema pulmonar & 5 & 2,03 & 0,60 \\
& Linfonodos hemais na superfície pleural & 4 & 1,62 & 0,48 \\
& Acompanhando descarte de coração & 3 & 1,21 & 0,36 \\
& Aspiração de conteúdo ruminal & 3 & 1,21 & 0,36 \\
& Aderência ao pericárdio & 3 & 1,21 & 0,36 \\
& Pleurisia & 1 & 0,40 & 0,12 \\
\hline
\end{tabular}

*FCTA=Frequência de Condenação no Total de Abates.

A aspiração de sangue, também lesão pulmonar, foi o segundo tipo de alteração mais importante, responsável por $17,88 \%$ do total de lesões e/ou causas de condenação observadas. Esta alteração também foi a segunda principal em bovinos abatidos em matadouro do Rio Grande do Sul (Fruet et al., 2013). Tembo e Nonga (2015) verificaram a hidatidose pulmonar como a segunda mais importante, enfermidade esta não observada no presente estudo. Lesões como hemorragia petequial, enfisema pulmonar, aspiração de sangue e aspiração de conteúdo ruminal são indicativas de falhas nas técnicas de abate, seja durante a insensibilização e/ou sangria, e são descartadas devido a questões estéticas, pelo aspecto repugnante que causam ao consumidor (Fruet et al., 2013). Dessa forma, a elevada frequência destas lesões indicam falhas no manejo de abate no abatedouro do presente estudo.

Hemorragia petequial representou $10,97 \%$ do total de lesões identificadas no pulmão. $\mathrm{Na}$ maioria das vezes (93\%) a lesão estava associada ao enfisema pulmonar, que foi a principal razão para descarte do pulmão, por ser mais facilmente perceptível durante a inspeção e por causar maior repúdio ao consumidor, deixando a hemorragia petequial como lesão de menor importância. Esta associação justifica o fato da hemorragia petequial não ser citada na literatura como causa de condenação durante o abate de bovinos. No mais, sua ocorrência e quantificação podem estar sendo subestimadas, já que a lesão necessita ser diferenciada macroscopicamente da aspiração de sangue, o que requer um exame criterioso, mas possível de ser realizado, especialmente com a prática de incisões no órgão.

Foram observados abscessos $(4,06 \%)$ e lesões sugestivas de tuberculose $(3,65 \%)$, que indicam falhas no manejo sanitário dos rebanhos e poderiam causar danos à saúde do consumidor, caso não fossem identificados e descartados na linha de inspeção (López, 2009). Com menor frequência também foram observadas: congestão pulmonar $(2,43 \%)$, que pode estar relacionada ao manejo de abate ou insuficiência cardíaca congestiva; pneumonia $(2,43 \%)$; atelectasia $(2,43 \%)$; edema pulmonar $(2,03 \%)$; presença de linfonodos hemais na superfície pleural $(1,62 \%)$, que apresentaram-se como múltiplos nódulos vermelho escuro de 1 a $2 \mathrm{~cm}$ de diâmetro que 
protuiam do parênquima pulmonar (Barros, 2010). Tais nódulos não causam nenhum dano à saúde do consumidor, caso consumido, porém determinam um aspecto repugnante na comercialização do órgão, o que leva a sua condenação. Em sequência, a condenação acompanhando descarte de coração $(1,21 \%)$, quando não havia uma lesão nos pulmões, mas pelo fato destes fazerem parte de um mesmo bloco ao abate, ambos foram descartados; aspiração de conteúdo ruminal $(1,21 \%)$; aderência ao pericárdio $(1,21 \%)$ e pleurisia $(0,4 \%)$.

Os descartes de fígado representaram $20,65 \%$ do total de condenações, o que fez desse órgão a segunda víscera com maior frequência de lesões e/ou causas de condenação (Tabela 1). O órgão foi condenado em 6,12\% (51/833) dos animais abatidos. Este resultado foi semelhante aos $4,37 \%$ verificados em matadouro do estado de São Paulo (Vechiato et al., 2011) e 6,4\% no Triângulo Mineiro, MG (Castro e Moreira, 2010), porém relativamente superior aos 3,8\% em Dodoma, Tanzânia (Tembo e Nonga, 2015). Por outro lado, relativamente inferior aos $43,5 \%$ em Atílio Vivacqua, ES (Vieira et al., 2011), 35,7\% em Santa Maria, RS (Fruet et al., 2013) e 25,7\% em Adama, Etiópia (Edo et al., 2014). Dos fígados condenados, $74,5 \%$ apresentaram apenas um tipo de lesão que determinou condenação, $21,56 \%$ dois e $3,92 \%$ três tipos na mesma víscera. Ao todo, foram registradas 70 alterações/lesões, distribuídas em nove diferentes tipos (Tabela 3).

Tabela 3. Lesões macroscópicas e/ou causas de condenação em fígados de bovinos abatidos no abatedouro público de Garanhuns - PE, no ano de 2014.

\begin{tabular}{llccc}
\hline Parte condenada & \multicolumn{1}{c}{ Causa e/ou lesão } & N & \% & FCTA* \\
\hline Fígado & Abscesso & 31 & 44,28 & 3,72 \\
& Telangiectasia & 13 & 18,57 & 1,56 \\
& Aderência ao diafragma & 10 & 14,28 & 1,20 \\
& Perihepatite & 7 & 10,00 & 0,84 \\
& Lesões sugestivas de tuberculose & 3 & 4,28 & 0,36 \\
& Hidatidose hepática & 2 & 2,85 & 0,24 \\
& Esteatose hepática & 2 & 2,85 & 0,24 \\
& Cirrose hepática & 1 & 1,42 & 0,12 \\
& Hepatomegalia & 1 & 1,42 & 0,12 \\
\hline Total & & $\mathbf{7 0}$ & $\mathbf{1 0 0}$ & - \\
\hline
\end{tabular}

*FCTA=Frequência de Condenação no Total de Abates.

A principal causa de condenação hepática foi a presença de abscesso, responsável por 44,28\% do total de lesões no órgão. Esta ocorreu em 3,72\% dos animais abatidos. Resultado relativamente semelhante de 2,4\% foi observado no Triângulo Mineiro, MG (Castro e Moreira, 2010), onde a lesão também foi relatada como a principal entre as hepáticas; 2,33\% em Adama, Etiópia (Edo et al., 2014); e 2,26\% em Atílio Vivacqua, ES (Vieira et al., 2011). Por outro lado, resultado inferior, de 0,4\%, foi encontrado em matadouro de Dodoma, Tanzânia (Tembo e Nonga, 2015).

A ocorrência de abscesso em ruminantes está relacionada a quadros prévios de ruminites, iniciadas por distúrbios digestivos, tais como acidose ruminal (Vechiato et al., 2011); onfaloflebites ou como complicação de reticulite e reticuloperitonite traumática (Barros, 2010). Segundo o RIISPOA (BRASIL, 2017), a ocorrência desta lesão em órgãos, com exceção do pulmão, ocasiona a sua condenação, enquanto as respectivas carcaças podem ter diversos destinos, a depender do seu estado geral e do acometimento de linfonodos regionais.

Estudos apontam a fasciolose hepática (distomatose) como a principal alteração em fígados condenados (Vieira et al., 2011; Fruet et al., 2013; Edo et al., 2014; Tembo e Nonga, 2015), o que diferiu do presente estudo, uma vez que tal parasitose não foi observada. A fasciolose tem distribuição mundial, principalmente em regiões onde as condições climáticas são adequadas ao desenvolvimento de moluscos, que atuam como hospedeiros intermediários do parasito. No Brasil, sua maior ocorrência é relatada no Rio Grande do Sul, Santa Catarina, Paraná, São Paulo, Minas Gerais, Rio de Janeiro, Goiás e Espírito Santo (Bennema et al., 2014).

No estudo, telangiectasia representou $18,57 \%$ do total de condenações de fígado, com frequência de $1,56 \%$ dentre o total de bovinos abatidos. Na literatura, são relatados resultados 
relativamente superiores, de 2,26\% (Vieira et al., 2011) e inferiores, de 0,59\% (Castro e Moreira, 2010). Outros estudos em matadouros de Santa Catarina, Minas Gerais e São Paulo apontam a lesão como a de maior importância para a condenação de fígado (Mendes e Pilati, 2007; Castro e Moreira, 2010; Vechiato et al., 2011). Esta, trata-se de uma dilatação cavernosa dos sinusoides em áreas onde hepatócitos foram perdidos, sendo uma lesão sem significado clínico e sua condenação se dá por razões estéticas (Barros, 2010), uma vez que seu aspecto poderia causar repúdio ao consumidor. Nos casos desta pesquisa, os fígados apresentaram lesão generalizada, o que ocasionou condenação total da víscera, conforme a legislação vigente (BRASIL, 2017).

Aderência ao diafragma teve frequência de $14,28 \%$ em relação ao total de condenações de fígado. A lesão ocorre como consequência da formação de abscesso em regiões do fígado que tenham íntimo contato com o diafragma, o que possibilita a aderência. Desta forma, trata-se de uma lesão secundária. Por outro lado, a alteração pode não mais apresentar processo infeccioso ativo, não representando riscos à saúde do consumidor, caso consumido (Mendes e Pilati, 2007). No Oeste e no Planalto de Santa Catarina (Mendes e Pilati, 2007) foi descrito resultado relativamente inferior ao presente estudo, uma vez que a aderência representou $6,0 \%$ do total de lesões, situação semelhante aos 3,66\% em Atílio Vivacqua, ES (Vieira et al., 2011).

Outras lesões observadas em fígados foram: perihepatite (10\%); lesões sugestivas de tuberculose $(4,28 \%)$, com macroscopia de nódulos multifocais; e hidatidose $(2,85 \%)$. Hidatidose hepática, também conhecida como equinococose, é uma doença parasitária, causada pelo cestódeo Echinococcus granulosus, caracterizada pela presença de lesões císticas (hidáticas) em órgãos parenquimatosos, especialmente fígado e pulmão (Barros, 2010). Sua ocorrência aparentemente está sendo descrita pela primeira vez na microrregião de Garanhuns, o que pode estar relacionado à escassez de estudos e/ou sua baixa ocorrência na região. Além disso, outra possibilidade seria os dois animais que apresentaram tal alteração hepática, serem oriundos de regiões com ocorrência da doença e trazidos para propriedades da microrregião. Em menor frequência, ainda foram observadas: esteatose $(2,85 \%)$; cirrose $(1,42 \%)$; e hepatomegalia $(1,42 \%)$.

As condenações de coração, par de rins e carcaça foram menos frequentes e dessa forma, apresentaram um menor quantitativo de lesões e/ou causas de condenação (Tabela 4), em relação às vísceras discutidas anteriormente.

Tabela 4. Lesões macroscópicas e/ou causas de condenação em carcaças, corações e pares de rins de bovinos abatidos no abatedouro público de Garanhuns - PE, no ano de 2014.

\begin{tabular}{|c|c|c|c|c|}
\hline Parte condenada & Causa e/ou lesão & $\mathbf{N}$ & $\%$ & FCTA* \\
\hline \multirow[t]{7}{*}{ Coração } & Hemorragia subepicárdica & 4 & 33,33 & 0,48 \\
\hline & Hipertrofia concêntrica & 2 & 16,66 & 0,24 \\
\hline & Pericardite & 2 & 16,66 & 0,24 \\
\hline & Miocardite & 1 & 8,33 & 0,12 \\
\hline & Lesões sugestivas de tuberculose & 1 & 8,33 & 0,12 \\
\hline & Massa tumoral & 1 & 8,33 & 0,12 \\
\hline & Atrofia serosa da gordura & 1 & 8,33 & 0,12 \\
\hline Subtotal & & 12 & 100 & - \\
\hline \multirow[t]{2}{*}{ Rins (par) } & Acompanhando descarte de carcaça & 2 & 50,00 & 0,24 \\
\hline & Acompanhando descarte de fígado & 2 & 50,00 & 0,24 \\
\hline Subtotal & & 4 & 100 & - \\
\hline \multirow[t]{2}{*}{ Rejeição total de carcaça } & Contusão generalizada & 1 & 50,00 & 0,12 \\
\hline & Lesões típicas de tuberculose & 1 & 50,00 & 0,12 \\
\hline Subtotal & & 2 & 100 & - \\
\hline $\begin{array}{l}\text { Rejeição parcial de carcaça } \\
\text { (pernil) }\end{array}$ & Fratura de fêmur & 2 & 100 & 0,24 \\
\hline Subtotal & & 2 & 100 & - \\
\hline Total & & 20 & - & - \\
\hline
\end{tabular}

*FCTA=Frequência de Condenação no Total de Abates. 
As condenações de coração representaram $4,05 \%$ do total de condenações observadas no presente estudo (Tabela 1). Além disso, uma frequência de $1,2 \%(10 / 833)$ do total de animais abatidos, semelhante ao $1,68 \%$ em Nekemte, Etiópia (Efrem et al., 2015). Porém, relativamente inferior aos 3,1\% em Adama, Etiópia (Edo et al., 2014) e 2,09\% em Santa Maria, RS (Fruet et al., 2013).

A principal causa de descarte do coração foi hemorragia subepicárdica, que representou 33,33\% do total de lesões cardíacas e frequência de $0,48 \%$ do total de animais abatidos (Tabela 4). Esta lesão decorre principalmente de quadros de septicemia ou anóxia (Ocariano et al., 2010), quando a falta de oxigenação tecidual durante o processo de abate pode ter levado ao aparecimento da lesão. Em outros estudos as principais causas de condenação do coração foram hidatidose (Efrem et al., 2015), presença de cistos calcificados (Tembo e Nonga, 2015), pericardite (Edo et al., 2014; Moje et al., 2014) e contaminação (Israel et al., 2014). Hipertrofia concêntrica representou $16,66 \%$ do total de lesões cardíacas, no presente estudo. Esta lesão se apresenta como um aumento da espessura da parede ventricular e diminuição da câmara cardíaca (Ocariano et al., 2010). De forma semelhante, pericardite representou $16,66 \%$ das causas de condenação da víscera, porém foi descrita como a principal causa de condenação do coração, com frequência de 57,10\% (Moje et al., 2014) e 50\% (Edo et al., 2014). Também foi observada miocardite $(8,33 \%)$, que trata-se do processo inflamatório do miocárdio, geralmente associado a doenças sistêmicas; lesões sugestivas de tuberculose $(8,33 \%)$, com macroscopia de nódulos multifocais; massa tumoral $(8,33 \%)$ sugestiva de neoplasia; e atrofia serosa da gordura $(8,33 \%)$, indicativo de que a gordura foi catabolizada, tal como ocorre no processo de inanição (Ocariano et al., 2010).

Em relação as condenações de rim, apenas $0,48 \%$ dos animais tiveram seus rins condenados, totalizando quatro pares de rins (Tabela 1), as quais não ocorreram devido à lesões no próprio órgão, mas sim, por acompanhar condenações de fígados e carcaças (Tabela 4). A frequência de condenação de rim, observada no presente estudo, foi expressivamente inferior a outros estudos realizados no Brasil, que relataram $29,66 \%$ no Acre (Israel et al., 2014); 23,7\% no Rio Grande do Sul (Fruet et al., 2013) e 14,6\% em Minas Gerais
(Castro e Moreira, 2010). Estes apontaram a isquemia, congestão, uronefrose, cisto renal e nefrite como principais causas de condenação da víscera, o que está de acordo com a legislação vigente, que regulamenta a condenação de rins com infecções ou lesões tais como nefrite, nefrose, pielonefrite, uronefrose e cisto urinário (BRASIL, 2017).

A condenação da carcaça completa ocorreu em $0,24 \%$ (2/833) dos bovinos abatidos e a mesma frequência $(0,24 \%)$ foi observada para a condenação de parte de carcaça - pernil (Tabela 1). Dessa forma, em 0,48\% dos animais, foi verificada a ocorrência de condenação de carcaça. Esse valor foi semelhante ao $0,15 \%$, encontrado em São Luís, MA (Silva et al., 2011), porém superior ao $0,05 \%$ em Dodoma, Tanzânia (Tembo e Nonga, 2015). As condenações totais de carcaça decorreram de contusão generalizada (50\%) e lesões caseosas e calcificadas, típicas de tuberculose $(50 \%)$, com frequência de $0,12 \%$ em relação ao total de animais abatidos (Tabela 4), conforme as regulamentações da legislação sanitária vigente (BRASIL, 2017). Já as duas condenações de pernil decorreram de fratura de fêmur. Estudo realizado em matadouro de São Luís - MA, relata que $0,0006 \%$ dos animais abatidos, apresentaram condenação por lesão típica de tuberculose e $0,03 \%$ para contusão (Silva et al., 2011), entretanto, as lesões de brucelose foram a principal causa de condenação de carcaça, além da ocorrência de linfadenite e abscesso, que não foram observadas na presente pesquisa. $\mathrm{O}$ transporte também é um ponto crítico do pré-abate e alguns fatores como superlotação do caminhão, diferentes faixas etárias transportadas em conjunto, mistura de animais de lotes diferentes e presença de animais muito ariscos podem favorecer a ocorrência de contusões e fraturas.

Diante do exposto, conclui-se que as principais causas de condenação, registradas no presente estudo, são imputáveis às falhas de manejo pré-abate e de abate inadequadas, que devem ser corrigidas, com o emprego de técnicas adequadas que garantam o bem-estar animal e o abate humanitário, de acordo com a legislação vigente no Brasil. Ainda, o registro de um maior número de lesões frente ao número de condenações chama a atenção para a importância do registro adequado das lesões e/ou alterações presentes em cada peça condenada, para que não ocorra a subnotificação. Desta forma, será possível uma melhor avaliação e monitoramento do perfil 
sanitário do rebanho bovino de corte da região, bem como da eficiência do manejo pré-abate e das técnicas de abate empregadas.

\section{Conflito de Interesse}

Os autores declaram não existir conflito de interesse.

\section{Referências}

Barros, C.S.L. Fígado, vias biliares e pâncreas exócrino. In: Santos, R.L.; Alessi, A.C. (Org.). Patologia veterinária. São Paulo: Roca, 2010. p.291-336.

Bennema, S.C.; Scholte, R.G.C.; Molento, M.B.; Medeiros, C.; Carvalho, O.S. Fasciola hepatica in bovines in Brazil: data availability and spatial distribution. Revista do Instituto de Medicina Tropical de São Paulo, 56(1): 35-41, 2014.

BRASIL. Ministério da Agricultura, Pecuária e Abastecimento. Regulamento da Inspeção Industrial e Sanitária de Produtos de Origem Animal - RIISPOA. Decreto $\mathrm{n}^{\circ}$ 9.013, de 29 de março de 2017; Regulamenta a Lei $\mathrm{n}^{\circ} 1.283$, de 18 de dezembro de 1950 e a Lei $\mathrm{n}^{\circ} 7.889$, de 23 de novembro de 1989. Brasília, 2017. Disponível em: $<$ https://www.saude.rj.gov.br/comum/code/M ostrarArquivo.php?C=NzU2NQ\%2C\%2C > Acesso em: 23 jan. 2018.

Castro, R.V.; Moreira, M.D. Ocorrências patológicas encontradas de rins e fígados bovinos em matadouro frigorífico do triângulo mineiro. Fazu em Revista, 7: 159-163, 2010.

Edo, J.J.; Pal, M.; Rahman, T. Investigation into major causes of organs condemnation in bovine slaughtered at Adama municipal abattoir and their economic importance. Haryana Veterinarian, 53(2): 139-143, 2014.

Efrem, L.; Serda, B.; Sibhat, B.; Hirpa, E. Causes of organ condemnation, its public health and financial significance in Nekemte municipal abattoir, Wollega, Western Ethiopia. Journal of Veterinary Medicine and Animal Health, 7(6): 205-214, 2015.

Fekadu, A.; Legesse, E.; Tesfaye, D. The Cause, Rate and Economic Implication of Organ Condemnation of Cattle Slaughtered at Jimma Municipal Abattoir, Southwestern Ethiopia. Global Veterinaria, 9(4): 396-400, 2012.

Fruet, A.P.B.; Fabrício, E.A.; Kirinus, J.K.; Scortegagna, A.; Dörr, A.C.; Nörnberg, J.L.
Perdas econômicas oriundas das condenações de vísceras bovinas em matadouros de Santa Maria, Rio Grande do Sul. Revista brasileira de Ciência Veterinária, 20(2): 99-103, 2013. IBGE. Instituto Brasileiro de Geografia e Estatística. Pecuária 2014. Estados Pernambuco. Disponível em: $<$ http://www.ibge.gov.br/estadosa/temas.php ?sigla $=$ pe\&tema=pecuaria2014 $>$. Acesso em: 16 mar. 2016.

Israel, L.F.S.; Duarte, M.T.; Carrijo, K.F. Principais causas de condenação em bovinos abatidos em um matadouro frigorífico sob inspeção oficial no município de Rio Branco, Acre, Brasil. Enciclopédia biosfera, 10(19): 1549-1562, 2014.

Lima, M.F.C.; Suassuna, A.C.D.; Ahid, S.M.M.; Filgueira, K.D. Análise das alterações anatomopatológicas durante a inspeção post mortem em bovinos no abatedouro frigorífico industrial de Mossoró, Rio Grande do Norte. Ciência Animal, 17(2): 113-116, 2007.

López, A. Sistema respiratório. In: McGavin, M.D.; Zachary, J.F. (Org.). Bases da patologia em veterinária. 4 ed. Rio de Janeiro: Elsevier, 2009. p. 463-558.

Mendes, R.E.; Pilati, C. Estudo morfológico de fígado de bovinos abatidos em frigoríficos industriais sob inspeção estadual no Oeste e no Planalto de Santa Catarina, Brasil. Ciência Rural, 37(6): 1728-1734, 2007.

Moje, N.; Abdeta, D.; Kebede, S.; Terfa, T.; Desissa, F.; Regassa, A. Major Causes of Organs and Carcass Condemnation in Cattle Slaughtered at Nekemte Municipality Abattoir, East Wollega, Ethiopia. Global Veterinaria, 13(3): 278-284, 2014.

Ocariano, N.M.; Paixão, T.A.; Carvalho, E.C.Q.; Gimeno, E.J. Sistema Cardiovascular. In: Santos, R. L.; Alessi, A. C. (Org.). Patologia Veterinária. São Paulo: Roca, 2010. p. 51-88.

Pinto, P.S.A. Inspeção e higiene de carnes. Viçosa: Editora UFV, 2008. 320p.

Sampaio, I.B.M. Estatística aplicada à experimentação animal. 2 ed. Belo Horizonte: Fundação de Estudo e Pesquisa em Medicina Veterinária e Zootecnia, 2002. 265 p.

Santos, R.L.; Guedes, R.M.C. Sistema Respiratório. In: Santos, R.L.; Alessi, A.C. (Org.). Patologia veterinária. São Paulo: Roca, 2010. p. 291-336. 
Santos I.S.; Mano, S.B.; Tortelly, R.S.; Souza, M.L.; Silva, D.A.S. Estudo da localização do Cysticercus bovis em corações de bovinos abatidos sob inspeção. Higiene Alimentar, 15(89): 37-44, 2001.

Silva, M.C.A.; Mendonça, G.A.; Soares, D.B.; Bueno, J.P.R. Alterações anatomopatológicas identificadas na inspeção Post mortem em bovinos no abatedouro frigorífico no município de Uberlândia - MG. Enciclopédia Biosfera, 9(17): 82-89, 2013.

Silva, V.C.; Vieira, H.O.; Duarte, T.M. Principais causas de condenações de carcaças em matadouros bovinos sob inspeção municipal na cidade de São Luís - MA. Revista Higiene Alimentar, 25(194/195): 553-554, 2011.

Sodré, A.F.U.; Trevisan, A.B.; Vasconcelos, E.S.; Moura, D.V.B.; Vieira Neto, J.; Silva, M.C.A. Principais causas de condenação de bovinos abatidos em matadouro- frigorífico sob inspeção estadual no estado da Bahia. Revista
Higiene Alimentar, 25(194/195): 555-556, 2011.

Tembo, W.; Nonga, H.E.A survey of the causes of cattle organs and/or carcass condemnation, financial losses and magnitude of foetal wastage at an abattoir in Dodoma, Tanzania. Onderstepoort Journal of Veterinary Research, 82(1): 1-7, 2015.

Vechiato, T.A.F; Maschio, W.; Bom, L.C.; Lopes, P.D.; Ortolani, E.L. Estudo retrospectivo de abscessos hepáticos em bovinos abatidos em um frigorífico paulista. Brazilian Journal of Veterinary Research and Animal Science, 48(5): 384-391, 2011.

Vieira, N.P.; Faria, P.B.; Mattos, M.R.; Pereira, A.A. Condenação de fígados bovinos na região sul do estado do Espírito Santo. Arquivo Brasileiro de Medicina Veterinária e Zootecnia, 63(6): 1605-1608, 2011. 